\title{
Effect of Environmental Conditions on the Dehydration and Performance of Fire-Protective Gels
}

\author{
Jacob Kadel, University of North Carolina at Charlotte, Charlotte, NC, USA \\ Faraz Hedayati and Stephen L. Quarles, Insurance Institute for Business \& \\ Home Safety, Richburg, SC, USA \\ Aixi Zhou (10*, North Carolina A\&T State University, Greensboro, NC, USA
}

Received: 3 February 2020/Accepted: 10 September 2020

\begin{abstract}
During wildfire events fire-protective gels can be used as a line of defense to protect structures. The effectiveness of freshly applied gels in delaying ignition and flame growth on structures has been well established. However, in a real-world scenario there is a period between the application of the gel and the arrival of a spot fire or the fire-front. During this period, the gels are often exposed to extreme conditions consisting of high winds and low relative humidity. The effect of these weathering conditions on the performance of fire-protective gels is still poorly understood. This study examined the dehydration and performance of fire-protective gels following a range of weathering conditions. Two commercially available gels were applied to a $100-\mathrm{mm}$ by $100-\mathrm{mm}$ T1-11 plywood sample and then artificially weathered in an environmental chamber, with controlled temperature, relative humidity, and wind. The remaining mass of the gels was measured at selected intervals to determine the relationship between mass loss and dehydration related to weathering. A second series of tests was conducted on weathered T1-11 samples at specific mass loss states as well as on freshly applied gels using a $50 \mathrm{~kW} / \mathrm{m}^{2}$ heat flux exposure utilizing a cone calorimeter. Results indicated that they dehydrated to the point where, after $3 \mathrm{~h}$, fire performance was no better than the uncoated wood samples and the gels could facilitate ignition. This timeline suggests that gels should only be applied by first responders and homeowners should focus on evacuation related activities.
\end{abstract}

Keywords: Wildfire, Fire-protective gels, Weathering, Fire protection

\section{Introduction}

Wildfires pose a threat to communities located in or near wildland areas across the nation. This threat has been increasing over the last several decades [1]. The Camp Fire in Northern California resulted in more than 80 fatalities and destroyed more than 18,000 buildings. The Camp Fire followed other recent destructive fires in California (e.g., Valley, Butte, Tubbs and Thomas) and other

\footnotetext{
* Correspondence should be addressed to: Aixi Zhou, E-mail: azhou@ncat.edu
} 
locations in the United States and Canada (e.g., 2016 Chimney Tops 2 in Gatlinburg Tennessee and 2016 fire in Fort McMurray, Alberta, Canada). The 20192020 bushfires in Australia affected 18.6 million hectares. Home and business losses during these fires demonstrate the need for more effective building codes and mitigation strategies to reduce building ignitions during wildfires.

Wildfire mitigation strategies for buildings can be divided into two broad categories: passive and active. Passive strategies are the actions taken when wildfire is not threatening and are intended to have long-term benefits. For example, use of less vulnerable construction materials and installation designs. Another possible passive strategy is an intumescent coating. When applied to a vulnerable substrate, such as a combustible cladding, intumescent coatings function by developing a thermal insulating layer once chemicals included in the coating are activated by exposure to sufficient heat. These coatings can swell 20 to 50 times their original thickness, forming a carbonaceous-rich layer between the substrate material and heat source. A study reported that weathering drastically reduced their effective service life of the intumescent coating much less than that reported in the product marketing literature [2].

In contrast to passive mitigation strategies, active strategies are intended to be implemented just prior to a building being threatened and therefore a limited effective service life (in the order of hours to days) is expected [3-5]. In some cases, a particular passive mitigation strategy (e.g., covering attic vents and/or use of a thermal blanket or building wrap) is reversed when the threat has passed (i.e., the vent cover or blanket or wrap is removed). In the case of an application of a gel, it would be washed off once the threat has passed. Fire protective gels are made with superabsorbent polymers that hold large amounts of water. Once the gel is applied, the water absorbed polymers layer themselves on the substrate (one on top of the other). Once exposed to heat, the stored water in the gel begins to evaporate until the water molecules are depleted.

The effectiveness of freshly applied fire-protective gels on stalling and/or suppressing ignition and fire growth has been established in previous studies. Freshly applied gels greatly increased time to ignition under various heat exposures [5-7]. Madrzykowski et al. [8] reported on a study where exterior sidings were sprayed with two different gelling agents and exposed to a $50-\mathrm{kW}$ fire (burner) for $10 \mathrm{~min}$. In this study, it was concluded that gelling agents applied to combustible sidings reduced the likelihood of ignition and flame spread. The gel applications in this research were applied $15 \mathrm{~min}$ prior to exposure to a $50-\mathrm{kW}$ fire in a laboratory where environmental conditions were maintained between $21-27^{\circ} \mathrm{C}\left(69.8-80.6^{\circ} \mathrm{F}\right)$ and relative humidity between $45-70 \%$. The study acknowledged the need for further research under more realistic (wildfire) weather conditions. A follow up study was conducted in 1999 [9] where the objective was to assess the suitability of an intermediate-scale calorimeter (ICAL) to evaluate fire protective gels and establish the basis for future standard test development and product evaluation. The primary interest in this study was time to ignition. It was observed that the application of the gel was not uniform (i.e., coating thickness varied between very thin and very thick), which resulted in variability in the performance of a given substrate. Locations where coating application was thin were first to ignite under the 
radiant heat exposures $\left(15 \mathrm{~kW} / \mathrm{m}^{2}\right.$ and $\left.25 \mathrm{~kW} / \mathrm{m}^{2}\right)$. Due to application difficulties, it was reported that "the true nature of the protective actions was not adequately evaluated". In this study, the gels were also "dried" after application on the plywood substrate by exposure to a $1 \mathrm{~kW} / \mathrm{m}^{2}$ heat flux for two time periods: 13 samples for less than 5 min (called "short drying time") and 2 samples for $60 \mathrm{~min}$. The relative humidity and temperature in these tests varied between $30-80 \%$ and $25.6-43.3^{\circ} \mathrm{C}\left(78-110^{\circ} \mathrm{F}\right)$, respectively, without any wind. Grand reported that drying had a "measurable effect" on gel treatments. As a continuation of Grand's research [9], different siding products were applied with water-based fire-protective gels and exposed to two different heat fluxes [10]. It was reported that an increase in time to ignition for wood siding, from $30 \mathrm{~s}$ to $300 \mathrm{~s}$, occurred for treated panels when exposed to a heat flux of $25 \mathrm{~kW} / \mathrm{m}^{2}$. The gels applied to windows extended the time to cracking and subsequent breakage of the window glass. The drying condition was created by exposing the samples to a $1 \mathrm{~kW} / \mathrm{m}^{2}$ for $1 \mathrm{~h}$ and $2 \mathrm{~h}$. It was concluded that this drying condition had little effect on time to ignition.

While there is clear evidence that fire-protective gels can increase the time to ignition when freshly applied, there has not yet been a systematic study of the effect of weathering. Exposing the samples to a $2-\mathrm{h} 1 \mathrm{~kW} / \mathrm{m}^{2}$ heat flux at room temperature and relative humidity does not realistically mimic wildfire weather. Since low relative humidity, high temperature, and strong winds are common in an actual wildfire [11] lack of information regarding performance after weathering is a deterrent to the more wide-spread use of gel products.

Effects of wind on the fire performance of the gels have been explored in [7]. In that study, "fire weather" was created by exposing samples to a $1 \mathrm{~kW} / \mathrm{m}^{2}$ heat flux for $60 \mathrm{~min}$ in the presence of a $9 \mathrm{~m} / \mathrm{s}(20 \mathrm{mph})$ wind. The critical flux for fire growth (CFFG) was chosen as a quantitative measure of fire performance. CFFG is defined as the minimum incident heat flux (mainly radiation) that leads to ignition and sustained flaming of a specimen after a 3-min exposure and in the presence of a $300-\mathrm{mm}$ (pilot) flame. CFFG was measured for different vegetation and structural fuels, with and without gel coatings. A "significant increase" in CFFG was reported for vegetation and structural fuels when the gel was fresh. However, CFFG was reduced from $20-25 \mathrm{~kW} / \mathrm{m}^{2}$ to $2-5 \mathrm{~kW} / \mathrm{m}^{2}$ when the gel was subjected to "fire weather" prior to the fire test. As a follow-up study to that by Urbas [7], a full-scale outdoor test was designed to validate the Cone Calorimeter and ICAL tests and to simulate fire conditions found during wildland and prescribed fires [5, 12]. The structures for these full-scale tests were mock-up assemblies consisting of a $12 \mathrm{ft} \times 8 \mathrm{ft}(3.7 \mathrm{~m} \times 2.4 \mathrm{~m})$ wall and a $12 \mathrm{ft} \times 4 \mathrm{ft}(3.7 \mathrm{~m} \times 1.2 \mathrm{~m})$ roof. The siding and roof materials were plywood and western redcedar respectively. Nominal heat flux of $50 \mathrm{~kW} / \mathrm{m}^{2}$ to the wall was provided by three stacks of weathered wood pallets which were burned during the tests. In addition, two ASTM E108 Type B firebrands were used in each test, one placed on the wall and the other attached to the roof assembly. A fire-protective gel, in a 5-gallon container, was applied using a nozzle system. The nozzle was adjusted to a structure protection setting using a fog pattern before applying. Two full-scale tests were conducted with different drying conditions which included a wind effect. The wind was provided by a large fan. The drying times for the two tests were $10 \mathrm{~min}$ and $60 \mathrm{~min}$ 
with the same forced wind speed of $4.7 \mathrm{~m} / \mathrm{s}(10 \mathrm{mph})$. The full-scale tests [5] showed that among the three different ignition-resistance materials on wood clad structures, gel was the easiest to apply. The gel showed good flame impingement resistance ability and no observable difference in protection effectiveness between the drying times of $60 \mathrm{~min}$ and $10 \mathrm{~min}$. However, despite of these studies, to the best of the authors' knowledge, no standard test method to evaluate performance of fire-protective gels was developed.

Red flag warnings [11] are often associated with a typical wildfire weather; $15 \mathrm{mph}(6.7 \mathrm{~m} / \mathrm{s})$ sustained wind, relative humidity $(\mathrm{RH})$ of $15 \%$, and temperature of $23.89^{\circ} \mathrm{C}\left(75^{\circ} \mathrm{F}\right)$ are the minimum criteria. This high wind and temperature and low RH accelerate the drying rate of the fire-protective gels. The objective of this study was to improve our understanding of the effect of weathering on the dehydration rate and subsequent fire performance of fire-protective gels. The results of this study can be used to define limitations and find the most efficient application time window.

\section{Experimental Procedure}

This research studied two correlated phenomena: the dehydration and resulting impact on fire performance of fire-protective gels. The flowchart showing the gel application and conditioning aspects of this experiment is shown in Fig. 1. Two different fire-protective gel types, designated as Gel A and Gel B, were evaluated. They are both qualified for use by the USDA Forest Service [13]. Gel A had a vegetable cooking oil mixing agent, and Gel B had a petroleum-based mixing agent. The gels were applied to the substrate following the manufacturers' application instructions and placed in an environmental chamber for conditioning. Mass loss was monitored by weighing and wet film thickness was measured and monitored using a wet-film gauge. This information was then used to assess the influence of weathered gels on fire performance. Fire tests were conducted using a cone calorimeter.

For weathering tests, $6.4 \mathrm{~mm}(0.25$ inch $)$ thick acrylic glass was originally chosen as the substrate material to eliminate the effect of moisture sorption and isolate the mass loss variable during dehydration (i.e., confine the mass loss measurement to the gel). The first series of tests were conducted for Gel A on $100 \times 100 \mathrm{~mm}(3.9 \times 3.9 \mathrm{inch})$ acrylic samples. After applying the gel (to $6.4 \mathrm{~mm}$ ( 0.25 inch) thickness per manufacturer's recommendation), combined mass and the gel thickness were measured using a precise mass balance $(0.001 \mathrm{~g}$ resolution) and a wet film gauge. Observations made during the application of Gel B on acrylic indicated that it did not adhere to the substrate. This will be explained in detail in Sect. 3. Hence, T1-11 panelized plywood was chosen as the substrate for this phase of the experiment. T1-11 panels were the material already selected for the fire performance tests as explained in the next paragraph. The T1-11 samples were the same dimension as the acrylic samples.

For fire performance tests, the gels were applied on oven-dried T1-11 panelized plywood according to the gel manufacturer's recommended thickness of $6.4 \mathrm{~mm}$ 


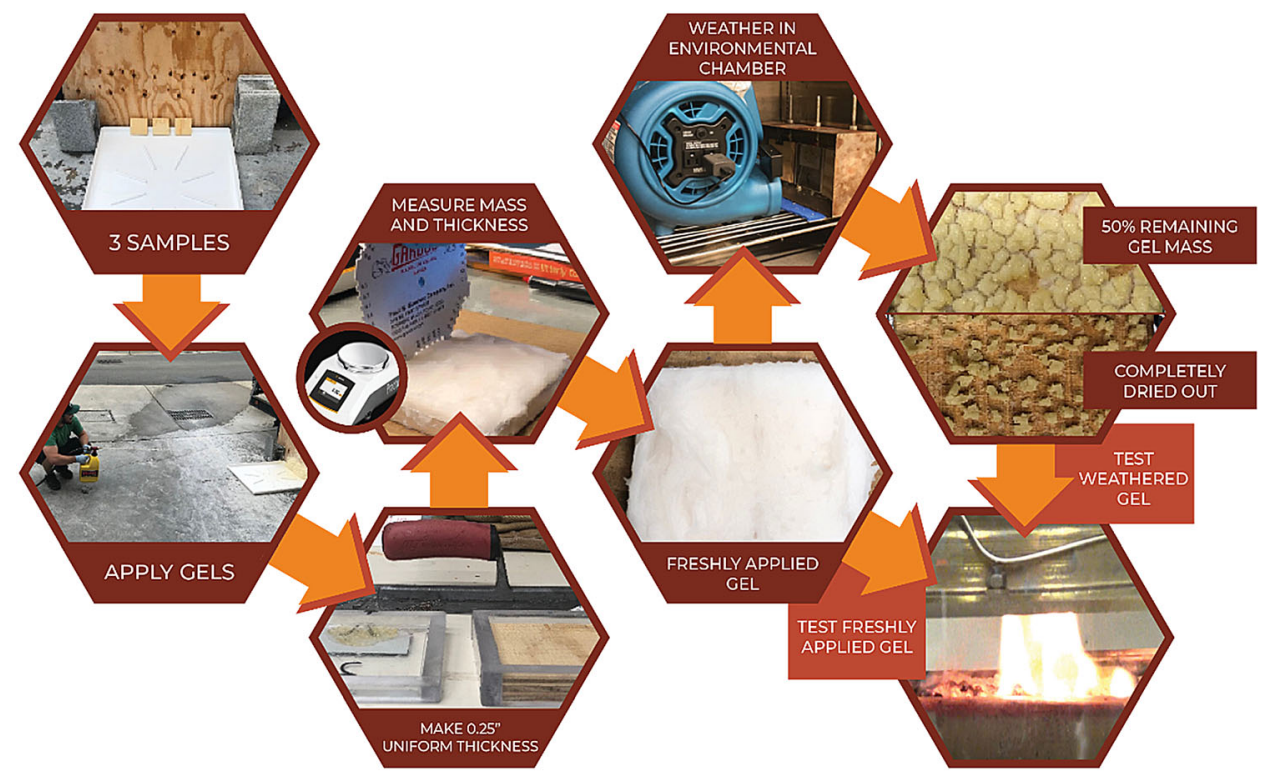

Figure 1. Overview of the experiment.

(0.25 inch). The uniform thickness was created by placing a 0.25 -inch-thick frame around the samples and remove the remaining with a trowel. T1-11 plywood was chosen as the substrate since is an available and commonly used siding in the western United States. The size of the T1-11 panel $[1.2 \times 2.4 \mathrm{~m}(4 \times 8 \mathrm{ft})]$ enabled preparation of many samples from one parent board, reducing between sample variability. The T1-11 plywood had a nominal thickness of $15.0 \mathrm{~mm}$ (0.594 inch) and actual thickness of $14.3 \mathrm{~mm}(0.563 \mathrm{inch})$. The moisture of the substrate T1-11 material was removed following the oven-dry method per ASTM D4442 [14]. Once the wood was completely dried out, they were sealed by double bagging using plastic bags until the fire tests was performed. Using the drying rate data from the weathering tests, two different sets of gel-coated samples were weathered for a time sufficient to (1) lose $50 \%$ of their initial mass or (2) reach their steady state mass. Steady state mass was defined as the point where the normalized (by initial mass) difference between two back-to-back measurements was below 0.03 (or $3 \%$ ). This number considered the sensitivity of the scale, windy condition in the chamber, and gel fall-off. The specimens' mass measurement was recorded every $30 \mathrm{~min}$ for the first $2 \mathrm{~h}$ and every hour for the remainder of the test. The fire performance of the test samples was then conducted using a Cone Calorimeter that exposed samples to a $50 \mathrm{~kW} / \mathrm{m}^{2}$ heat flux. Key fire performance parameters such as Heat Release Rate (HRR) and time-to-ignition ( $\left.\mathrm{t}_{\mathrm{ig}}\right)$ were measured and analyzed. 


\subsection{Environmental Chamber Dehydration Test}

After applying the gels, the samples were placed in the environmental chamber (Espec BTL-433) in a vertical orientation. The samples were held upright using a magnetic fastening device. The environmental chamber controlled relative humidity and temperature. Wind speed was controlled by placing a fan inside the chamber. Wind speed was controlled by increasing or decreasing the supply voltage. Wind speed was measured by an anemometer that was placed inside the chamber. The desired wind speed was documented for all experiments with a remotely-controlled camera focused on the anemometer screen. The camera could be viewed remotely from a handheld device with the chamber door closed to set the windspeed from the fan. Once the input voltages were determined, that set point was consistently used for all experiments. Tests at all wind speed and relative humidity combinations were replicated three times, for a total of 27 tests for each gel.

The environmental chamber had a controllable relative humidity $(\mathrm{RH})$ range from $10 \%$ to $95 \% \mathrm{RH}$, and a controllable temperature range from $-20^{\circ} \mathrm{C}$ to $180^{\circ} \mathrm{C}$. Environmental conditions used during these experiments included:

- Relative humidity levels: $15 \%, 40 \%$, and $70 \%$

- Temperature: fixed at $32.2^{\circ} \mathrm{C}\left(90^{\circ} \mathrm{F}\right)$

- Wind speed: $0 \mathrm{~m} / \mathrm{s}(0 \mathrm{mph}), 5 \mathrm{~m} / \mathrm{s}(11.2 \mathrm{mph})$, and $10 \mathrm{~m} / \mathrm{s}(22.4 \mathrm{mph})$

The mass and wet film thickness were recorded every $30 \mathrm{~min}$ for the first $2 \mathrm{~h}$ of exposure and then every hour for the remainder of the test. The tests were considered complete once the mass reached steady state. Since the initial mass of the samples was not the same, all mass measurements were normalized based on initial samples' gel mass. Results will be discussed in Sect. 3. The same procedure was used for all combinations of wind speed and relative humidity tests.

\subsection{Cone Calorimeter Fire Performance Test}

To evaluate the fire performance of the gels, new samples were prepared similar to the procedure explained in Sect. 2.1. The fire-protective gels were applied on $100 \times 100 \mathrm{~mm}(3.9 \times 3.9 \mathrm{inch}) \mathrm{T} 1-11$ plywood specimens and then placed in the environmental chamber for the specified conditioning period (based on the results in Sect. 2.1) before subjecting them to the radiant heat exposure in the cone calorimeter at $50 \mathrm{~kW} / \mathrm{m}^{2}$ per procedures in ASTM E1354 [15]. Three specific dehydration points were chosen: (1) freshly applied gel (designated as dehydration point 1 or DP1), (2) $50 \%$ remaining gel mass (designated as dehydration point 2 or DP2), and (3) steady state mass (dried out, designated as dehydration point 3 or DP3). Three replicates of each experimental dehydration point (described above) was evaluated (i.e., 9 tests per gel). 


\section{Results and Discussions}

A general observation when spraying the gels was that the nozzle clogged several times and a high-pressure air compressor was used to unclog the nozzle. This poses a great risk for homeowners defending their properties.

\subsection{Dehydration Test Results}

During dehydration tests it was observed that Gel B did not adhere well to the acrylic specimens (Fig. 2-right hand side column). Note that the manufacturer specifically stated it would adhere in their technical sheets. This finding indicated the need for validation tests on gel products. This observation demonstrated a potential vital weakness in certain gel products for glass. This weakness being that windows in a wildland fire would be a potential area prone to breakage due to the gel sloughing off and not offering protection.

To evaluate ways to improve gel adherence to the substrate, the acrylic was covered with sandpaper and then Gel B was applied. This procedure was not an effective method for improving the adherence of the gel, as depicted in Fig. 2. Hence, using the same dehydration methodology for Gel A, Gel B was evaluated using T1-11 plywood.

The fire performance tests were conducted on T1-11 plywood samples for both gel types at the three dehydration points described in Sect. 2.2. These dehydration points are shown in Fig. 3. Nine cone calorimeter tests were conducted for each gel type. As a control group, three cone tests were conducted on uncoated T1-11 plywood samples. The results of the fire performance tests are shown in Sect. 3.1 and the results of weathering (dehydration) in Sect. 3.2.

\subsection{Fire Performance Test Results}

Of all parameters that the cone calorimeter measures, the HRR curves and specifically their peak (PHRR), have often been a focus of fire research because of their relevance in estimating fire risk [16-18]. Figure 4a and b display the HRR curves for T1-11 Gel A and Gel B at all dehydration points. Uncoated and dried-out specimens (i.e., dehydration point 3) ignited quickly (sustained flaming per ASTM E1354). Ignition occurred when the volatile gases were in sufficient supply to ignite from an external spark and sustain flaming [15]. For all specimens, after ignition, in the HRR increased quickly until the PHRR was achieved. For Gel A, both fresh gel (dehydration point 1 ) and 50\% remaining gel mass (dehydration point 2) showed delay of ignition. While for Gel B, only fresh gel (dehydration point 1) showed delay of ignition.

As can be seen in Fig. 4a and b, in all tests the PHRR occurred at the initial peak. A secondary peak occurred when the samples disintegrate, which increased the actual surface available for burning by some large and unknown factor. Beyond this point, measurements did not have a numerical meaning [16, 17]. Comparing PHRR of uncoated wood with DP1 and DP2 for Gel A, the gel caused a reduction in the peak by $39 \%$ and $23 \%$, respectively. This reduction for Gel B was about $36 \%$ percent at both DP1 and DP2. However, the PHRR was 


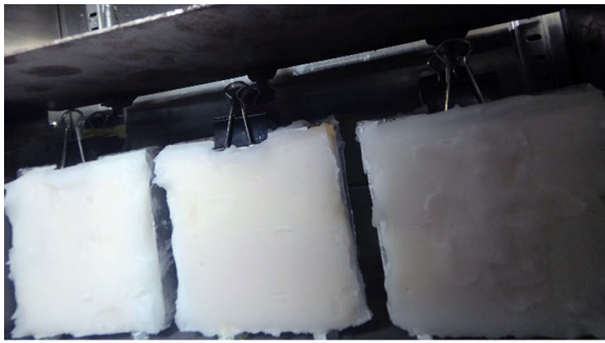

Gel A, Initial Application

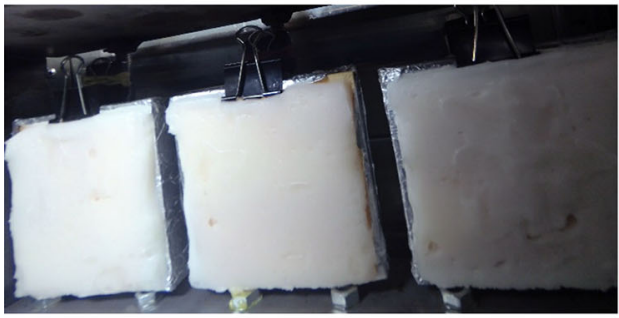

Gel A, 2 hours weathering

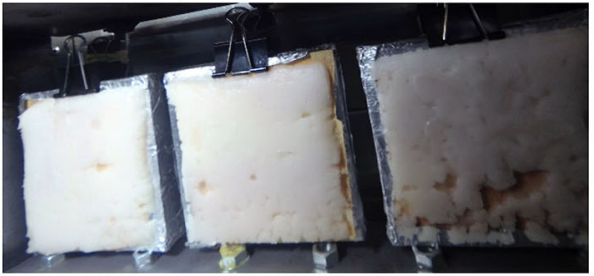

Gel A, 5 hours weathering

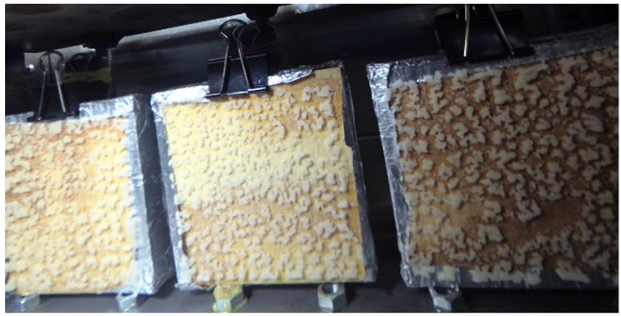

Gel A, Steady state mass

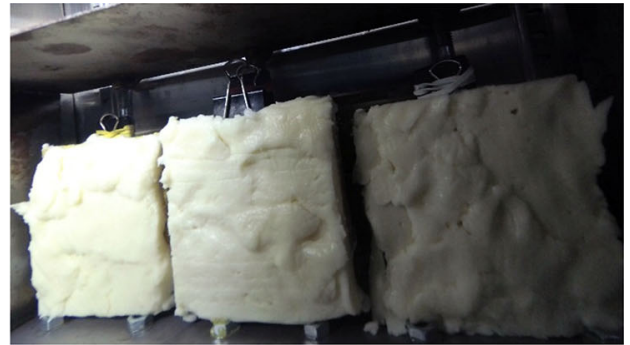

Gel B, Initial Application

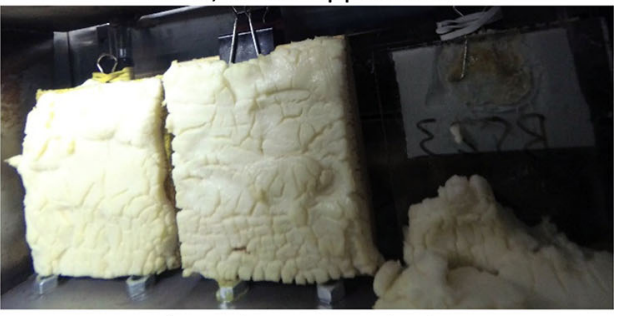

Gel B, 2 hours weathering

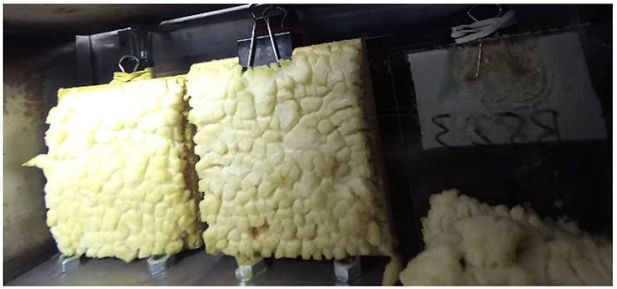

Gel B, 5 hours weathering

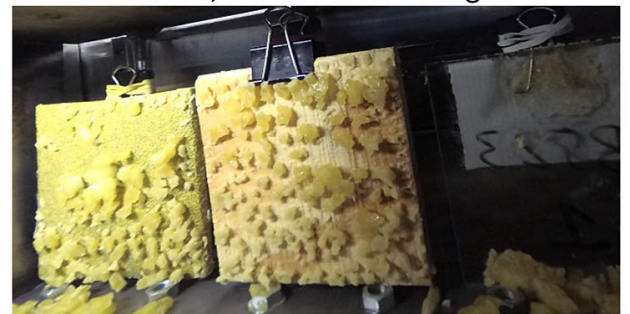

Gel B, Steady state mass

\section{Figure 2. Weathering in the samples positioned in the chamber,} maintained at $15 \%$ RH and a no wind condition.

larger at DP3 for both gels by about $20 \%$. This indicated the residue of the driedout gels acted as an additional fuel. The early rise at $15 \mathrm{~s}$ for Gel B at DP2 occurred because gel residues in some spots (due to unevenness of surface condition) ignited before the uncoated wood. In fact, immediate ignition occurred for two Gel B samples at DP2; one led to a sustained flaming (longer than $4 \mathrm{~s}$ ) and the other one extinguished shortly.

The averages and standard deviation of fire performance parameters are listed in Table 1. Considering the average values, one can observe that as the gels dehy- 


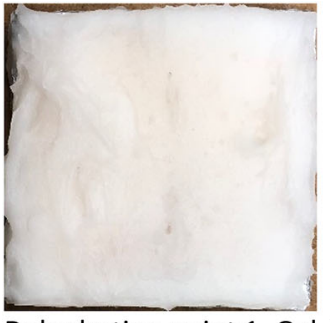

Dehydration point 1 , Gel A

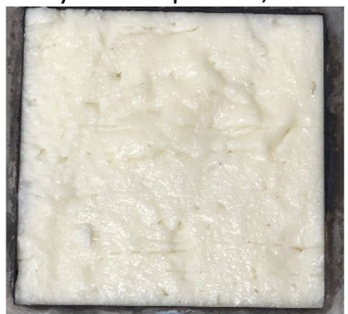

Dehydration point 1, Gel B

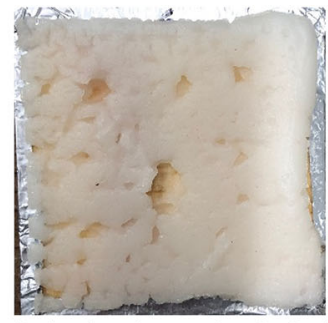

Dehydration point 2, Gel A

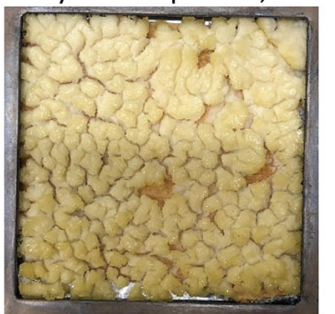

Dehydration point 2, Gel B

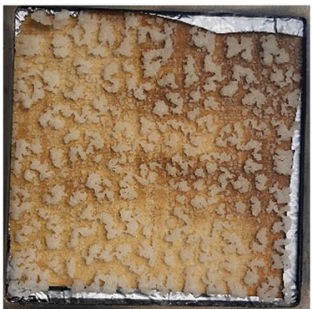

Dehydration point 3, Gel A

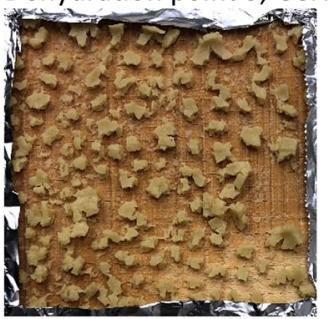

Dehydration point 3, Gel B

\section{Figure 3. Visual effects of weathering (Dehydration point 1 is freshly applied gel. Dehydration point 2 is $50 \%$ mass loss. Dehydration point 3 is the steady state condition).}

drated, their fire-protective properties diminished. In fact, at DP3, the average values of PHRR, HRR, and THR for both gels exceeded those of the T1-11 (uncoated) control samples. Comparing the average values of TTI of Gel A and Gel $\mathrm{B}$ to the T-11 controls, a negligible increase was observed for Gel A at dehydration point 3; however, for Gel B, TTI decreased by $73 \%$.

Table 1 also shows the mean and variability around the mean value in each measurement. For uncoated samples, the variability was a result of the heterogeneous structure of wood which has been previously observed. A $20 \%$ variability in PHRR and a 10\% variability in the 5-min average of HRR has been reported for 2 by 6-inch Douglas-fir lumber [16]. In this study, the variability of uncoated samples is about $13 \%$. For coated samples, the variability in fire performance parameters was a result of nonuniform thickness of gels after weathering the samples in a vertical orientation. Figure 3 shows the random dehydrated spots after weathering. Note that this happens in real-world applications and was not a flaw in the methodology of this paper. The study in [9] also reported difficulties in maintaining a uniform thickness even at the time of spraying the gels.

Table 1 shows that at DP3, the PHRR, first 1-min average HRR, first 3-min average HRR, and THR for both gels exceeded those of the uncoated T1-11 samples. Similarly, TTI became shorter than those of uncoated T1-11 at dehydration point 3. This indicated that after a certain amount of mass loss, the residue of both gels, but particularly Gel B, acted as an additional fuel, resulting in an increase in the energy released during combustion. Note that the effects of pressure-impregnated fire-protective treatments on wood is different than surface-applied gels. A $30 \%, 71 \%$ and $60 \%$ reduction in peak, first minute average and first 


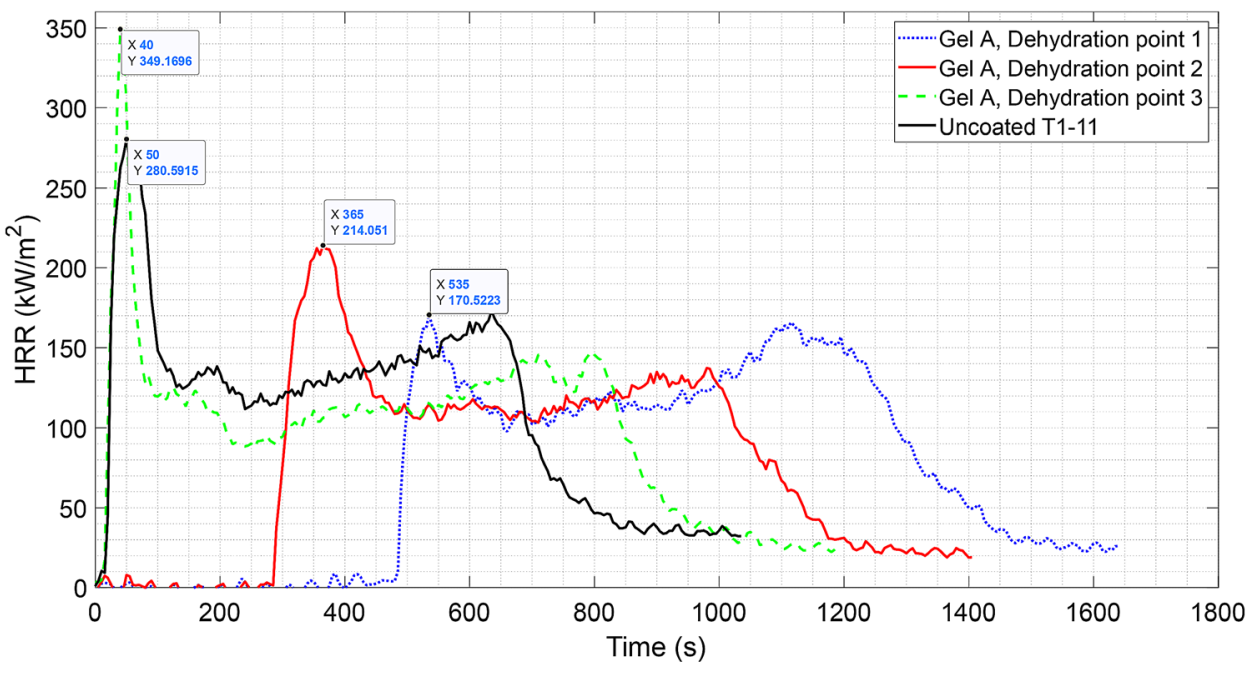

(a) HRR vs. Time for Gel A

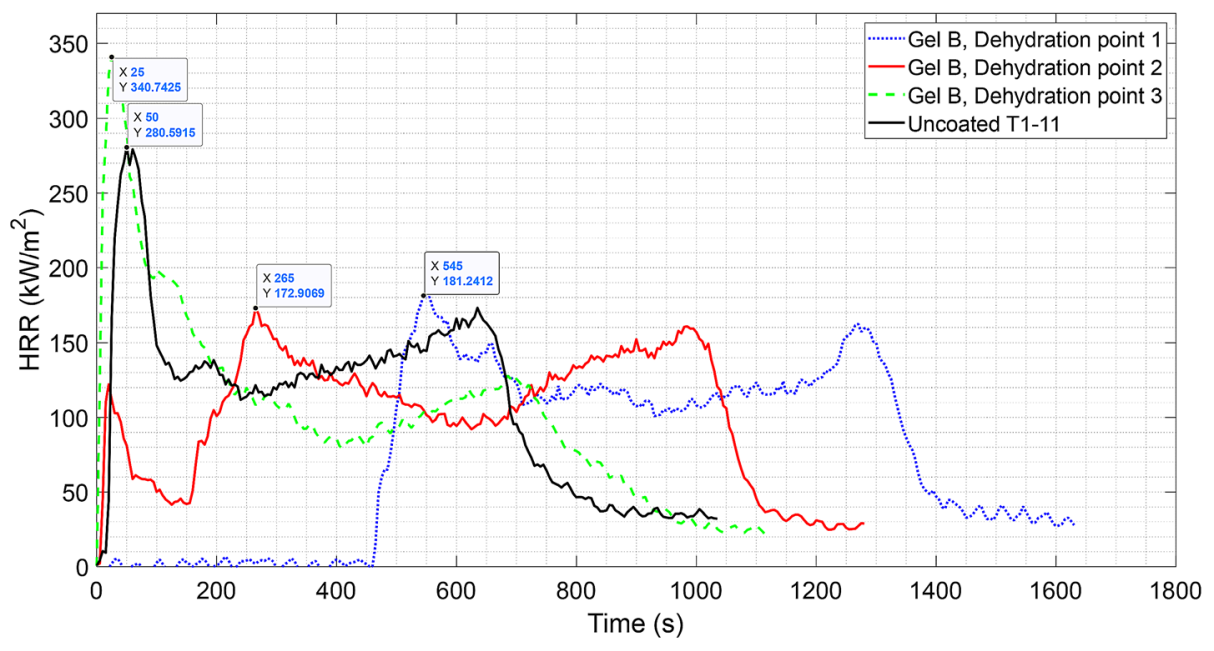

(b) HRR vs. Time for Gel B

\section{Figure 4. HRR histories of gels at different dehydration points: (a) HRR vs. Time for Gel A, (b) HRR vs. Time for Gel B).}

5-min average, respectively, in HRR of pressure-impregnated fire-protective treated wood were observed relative to untreated samples [16].

We propose that the remaining mass beyond which the fire performance properties of the coated sample decreased below that of the uncoated sample was taken as the Critical Remaining Mass (CRM). Its values in theory may range from 0 to 1 (or $0 \%$ or $100 \%$ ). The lower the CRM value, the better the fire protection per- 


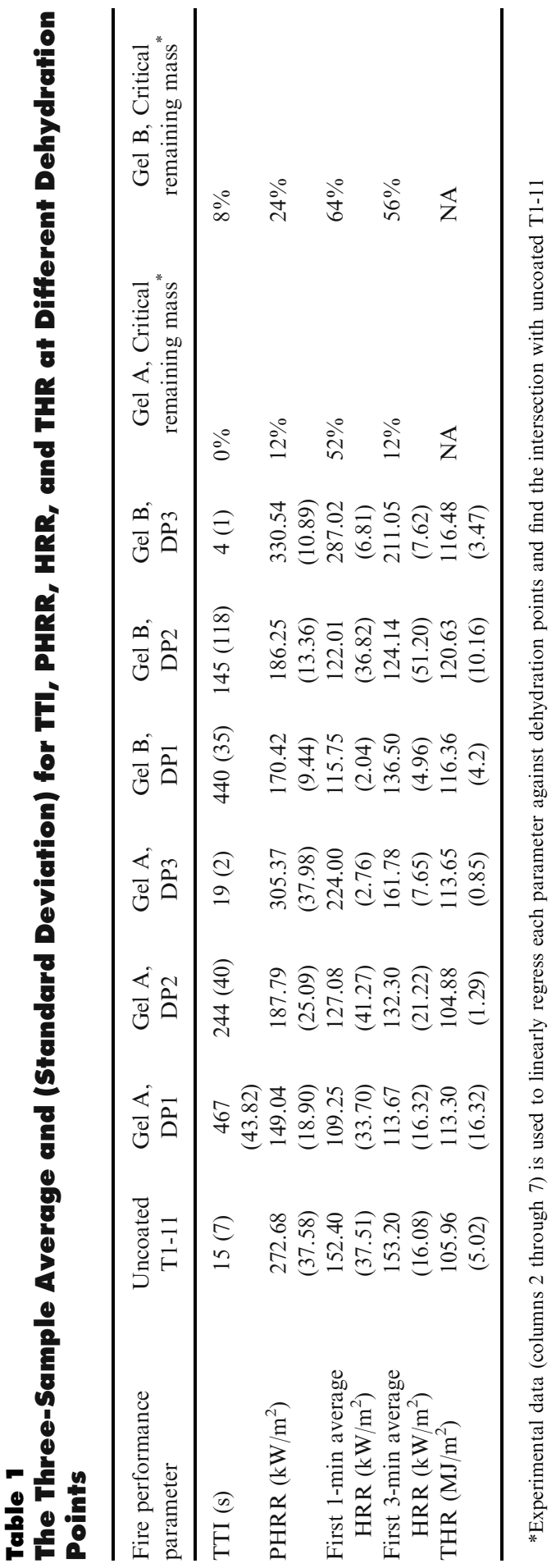


formance of the gel. A $0 \%$ CRM indicated that when the gel dried out, it left no residue and did not contribute to the burning of the wood sample. A 100\% CRM (at initial mass) indicated no protection from the gel when freshly applied.

Critical remaining mass occurred at some point between DP2 and DP3 for both gels, which can be estimated by regressing the parameters in Table 1 against the dehydration points. The last two columns of the table showed the critical remaining mass obtained from the intersection of a linear regression between a specific parameter versus dehydration points and those of uncoated T1-11. As can be seen, the critical remaining mass for Gel A was always lower than Gel B, indicating that the performance of Gel A was better than Gel B. Some of the critical remaining mass percentages might seem too high. For example, for Gel B, critical remaining mass regressed from first 3-min average HRR mean values was $64 \%$. Note that two out of three samples of Gel B ignited at dehydration point $2(50 \%$ remaining mass); one led to sustained flaming ( $>4 \mathrm{~s}$ ) and the other did not.

All parameters in Table 1 have a consistent trend with dehydration points except THR. Although at DP3, THR exceeded that of T1-11, the trend was not linear, and a meaningful linear regression was not available for this parameter. The fitted curve on mean values of TTI suggested $0 \%$ for Gel A. This suggested that Gel A always performed better than uncoated T1-11. However, the standard deviation between the samples was large enough to create an overlap between coated and uncoated samples. Hence, although the dehydrated gel diminished the fire performance, it was not reflected in the mean values. Considering the variability in the tests (discussed earlier), there was an overlap between TTIs and $0 \%$ which was not reflected in the mean values.

The critical remaining mass percentages listed in Table 1 were estimated using linear regressions. The $\mathrm{R}^{2}$ values for all lines were greater than 0.7. Any of these parameters could be used for further analysis. However, the parameters that represent the initial stages of the experiment (PHRR, first 1-min average HRR and first 3-min average HRR) would be more meaningful since ignition occurred during this period. It was reported that the relative uncertainty of HRR decreased with increasing HRR [18]. For this study PHRR was chosen for the remaining analysis. Table 2 represents the details of linear and exponential regressions for mean values of PHRR.

\section{Table 2}

Detail of Regression of PHRR vs Normalized Remaining Mass

\begin{tabular}{lll}
\hline Gel type & \multicolumn{1}{c}{$\mathrm{R}$-squared and regression type } & Parameters in fitted curve \\
\hline $\mathrm{A}$ & $\mathrm{R}^{2}=0.96$ & $\alpha=292.66$ \\
& $\mathrm{PHRR}=\alpha \mathrm{e}^{\beta \text { (remaining mass) }}$ & $\beta=-0.007$ \\
& $\mathrm{R}^{2}=0.92$ & $\alpha=-1.56$ \\
$\mathrm{PHRR}=\alpha \times$ remaining mass $+\beta$ & $\alpha=304.88$ \\
$\mathrm{~B}$ & $\mathrm{R}^{2}=0.85$ & $\beta=-0.007$ \\
& $\mathrm{PHRR}=\alpha \mathrm{e}^{\beta \text { (remaining mass) }}$ & $\alpha=-1.6$ \\
& $\mathrm{R}^{2}=0.82$ & $\beta=309.1$ \\
\hline
\end{tabular}




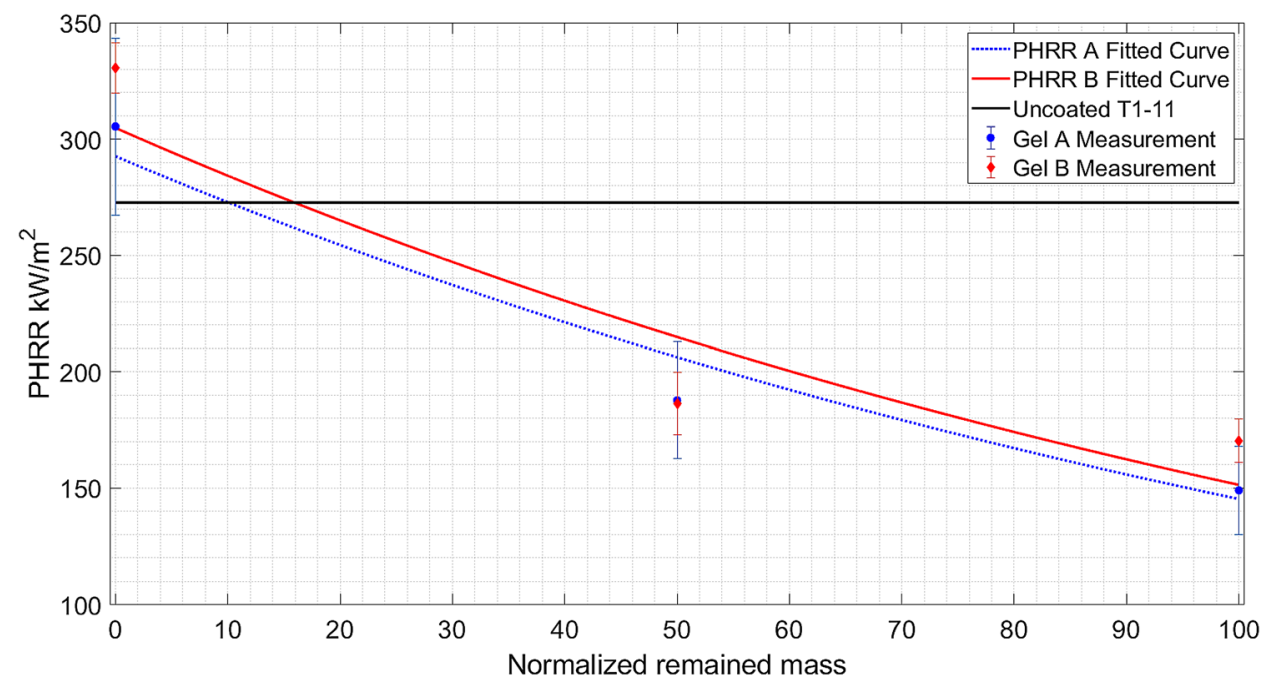

Figure 5. Fitted curve on mean PHRR at different dehydration points.

The $\mathrm{R}^{2}$ values for the exponential curve were greatest for both gels. These curves are compared with uncoated wood in Fig. 5. As can be seen, the intersection between the curves happens at $10 \%$ and $16 \%$ remaining mass for Gel $\mathrm{A}$ and $\mathrm{B}$, respectively. Beyond those points the PHRR of the coated samples exceeds that of the uncoated sample.

Environmental conditions altered the dehydration rates of gels. The time required to reach the critical remaining mass varies based on environmental conditions. Estimating this time would help first responders to make informed decisions about spraying time to benefit the fire-protective characteristics of the gels. This will be addressed in the following section.

\section{Discussion}

The two dependent variables, gel mass and gel thickness, were monitored during exposure to the indicated levels of wind and relative humidity. The results indicated that there was no recognizable pattern in thickness variation between the three measured locations (Fig. 3). Therefore, the remaining mass was selected as the response variable in evaluating the influence of wind, relative humidity, and time.

In Sect. 3.2 it was observed that $10 \%$ and $16 \%$ could be taken as critical remaining mass for Gel A and $\mathrm{B}$, respectively. The time to dehydrate $90 \%$ of Gel A and $84 \%$ of Gel B at different RH and wind speeds is plotted in Fig. 6 a and b. The Z-axis, time to reach critical value, was calculated by averaging the required time to reach critical mass loss threshold for three samples at each environmental condition. As previously mentioned, Gel B did not adhere to acrylic and was 


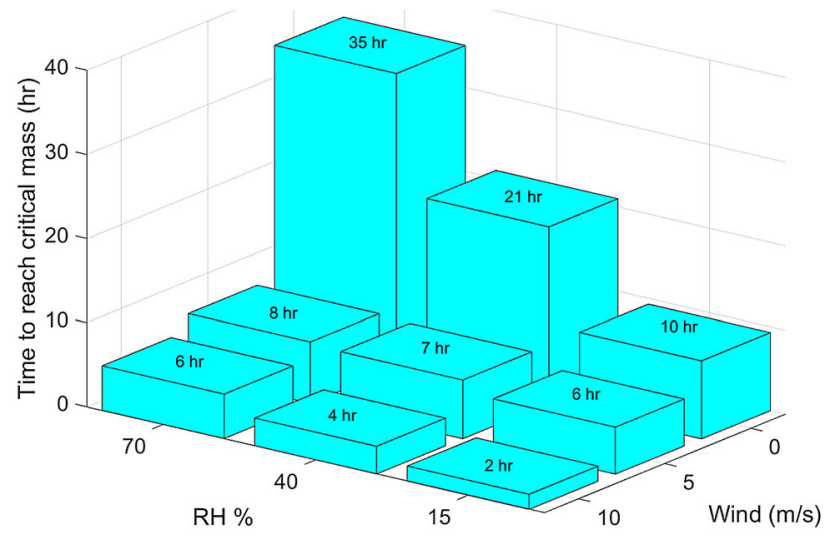

(a) Gel A

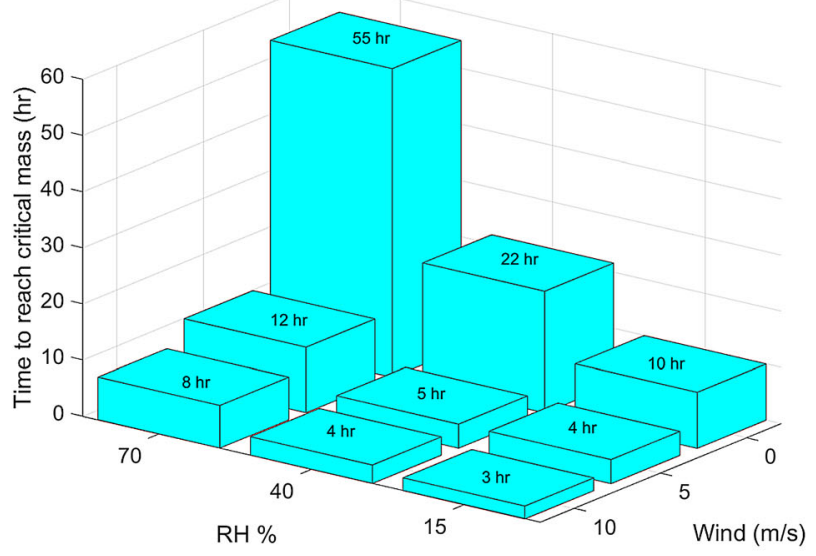

(b) Gel B

\section{Figure 6. Time to reach critical mass for gels (a) Gel A on acrylic (b) Gel B on T1-11.}

applied to T1-11. Different substrate materials need to be considered before direct comparison between weathering time of gels.

Two additional weathering tests $(15 \% \mathrm{RH}$, no wind and $15 \% \mathrm{RH}, 10 \mathrm{~m} / \mathrm{s}$ wind) were conducted for Gel A on plywood to compare similar substrate materials for both gels. Comparing the results of Gel A on wood and acrylic, it was observed the gel remained on the wood about 1.8 times as long as on acrylic. In 
other words, it takes about $3 \mathrm{~h}$ for Gel A to reach its critical remaining mass on T1-11.

Gel A exhibited a better performance in these experiments. However, during a wildfire event, the application of gels is somewhat independent of their fire performance and more relevant to their availability. Hence, the study suggests that, as a rule of thumb, first responders should not spray the gels more than $3 \mathrm{~h}$ before arrival of fire front or should be able to return and re-hydrate an already applied gel. Given this short time, these results suggested that homeowners should focus on evacuation rather than applying a gel product.

\section{Conclusions}

In this research the dehydration and fire performance characteristics of two type of gels were tested after simulated weathering: Gel A with a vegetable cooking oil mixing agent and Gel B with a petroleum-based mixing agent. Experimental results from this study showed that properly and freshly applied fire-protective gels are effective in protecting substrate material from ignition and reducing peak heat release rate after ignition.

The fire-protective gels' protective characteristics diminished as they weathered on being exposed to a drying environment. With the environmental chamber condition at $10 \mathrm{~m} / \mathrm{s}$ wind and $15 \% \mathrm{RH}$ at $32.3^{\circ} \mathrm{C}$, it took about $90 \mathrm{~min}$ for both gels to lose $50 \%$ on their initial mass. It took $7-9 \mathrm{~h}$, respectively, for both gels to completely dry out. Depending on the amount of dehydration that has occurred when the fire arrives, the gel residue can act as an additional fuel. The experimental results showed that at some point between 50\% mass loss and complete dehydration (i.e., at critical remaining mass), the fire performance parameters decreased below those of uncoated wood. Beyond this point, gels acted as an additional fuel and can facilitate ignition. Regressions from our experimental data suggested that the peak heat release rate of coated samples exceeded that of uncoated wood once gels were dehydrated about $85 \%$ or more.

Results from this study demonstrated that it took about $3 \mathrm{~h}$ for both gels to lose enough moisture to reach the critical remaining mass. Beyond this point, the gels acted as an additional fuel and facilitated ignition. Fire protective gels have been available as home kit nozzles and have been advertised to be used by homeowners to defend their houses when WUI fires occur. One key takeaway from this study is that, given the $3 \mathrm{~h}$ window, gels should only be applied by first responders and homeowners should use this time to evacuate. Caution should be taken to generalize the results of this laboratory study to real-world recommendations. Further studies should be carried out to provide a better understanding of the underlying mechanisms of the observed dehydration behavior and reduction in protection effectiveness. 


\section{Acknowledgements}

The authors would like to thank anonymous reviewers, Greg Mesa, Dr. Murray Morrison, Dr. Vahid Hemmati, Heather Estes, Noah Bull, Juan Battle, Daniel Gorham, Brent Henzi, and Brenna Meisenzahl for assisting with data collection and sharing their ideas and expertise.

\section{Open Access}

This article is licensed under a Creative Commons Attribution 4.0 International License, which permits use, sharing, adaptation, distribution and reproduction in any medium or format, as long as you give appropriate credit to the original author(s) and the source, provide a link to the Creative Commons licence, and indicate if changes were made. The images or other third party material in this article are included in the article's Creative Commons licence, unless indicated otherwise in a credit line to the material. If material is not included in the article's Creative Commons licence and your intended use is not permitted by statutory regulation or exceeds the permitted use, you will need to obtain permission directly from the copyright holder. To view a copy of this licence, visit http://creat ivecommons.org/licenses/by $/ 4.0 /$.

\section{References}

1. Tedim F, Leone V, Amraoui M, Bouillon C, Coughlan MR, Delogu GM et al (2018) Defining extreme wildfire events: difficulties, challenges, and impacts. Fire 1(1):9. https://doi.org/10.3390/fire1010009

2. Bahrani B, Hemmati V, Zhou A, Quarles SL (2018) Effects of natural weathering on the fire properties of intumescent fire-retardant coatings. Fire Mater 42:413-423

3. Takahashi F (2019) Whole-house fire blanket protection from wildland-urban interface fires. Front Mech Eng 5:60

4. Green A. Sprinkler systems for the protection of buildings from wildfire. Ph.D. Dissertation, University of Wollongong. 2019

5. Zhou A. Performance evaluation of ignition-resistant materials for structure fire protection in the WUI. In: Proceedings of the 13th International Conference and Exhibition on Fire and Materials (Fire and Materials 2013), San Francisco, California. 2013; Pages $355-66$

6. de Bruijn P. Testing a method to evaluate the effectiveness of water-enhancing gel on vertical surfaces. FPInnovations Wildfire Operations Research, Hinton, Alberta, Canada. 2010

7. Urbas J (2013) Effectiveness of pre-applied wetting agents in prevention of wildland Urban interface fires. Fire Mater 37:563-580

8. Madrzykowski DM, Roadarmel G, DeLauter LA. Durable Agents for Exposure Protection in Wildland/Urban Interface Conflagrations (NISTIR 6030). 1997

9. Grand AF. Report on a study to utilize the ICAL apparatus for the determination of the effectiveness of fire resistant durable agents. 1999 
10. Grand AF, Mehrafza M. Evaluation of the effectiveness of fire resistant durable agents on residential siding using an ICAL based testing protocol. Proc Fire Mater 2001;22-4

11. Tedim F, McCaffrey S, Leone V, Delogu GM, Castelnou M, McGee TK, et al. What can we do differently about the extreme wildfire problem: An overview. In: Tedim F, Leone V, McGee TK, editors. Extreme Wildfire Events and Disasters. Elsevier. 2020; Pages 233-63

12. Broyles G. Structure Protection Materials Evaluation. Technical Report 1251 1811-SDTDC, United States Department of Agriculture San Dimas Technology and Development Center, San Dimas, CA, October. 2014; Pages 1-16

13. US Forest Service. Water Enhancers for Wildland Fire Management. Washington, July 16, 2019. Available at https://www.fs.fed.us/rm/fire/wfcs/documents/2019\%20qpl_we_20 19-July.pdf

14. ASTM D4442-20, Standard Test Methods for Direct Moisture Content Measurement of Wood and Wood-Based Materials, ASTM International. 2020

15. ASTM E1354-17, Standard Test Method for Heat and Visible Smoke Release Rates for Materials and Products Using an Oxygen Consumption Calorimeter. ASTM International. 2017

16. Chamberlain DL. Heat release rate properties of wood-based materials. Gaithersburg, MD. 1983

17. Lowden LA, Hull TR (2013) Flammability behaviour of wood and a review of the methods for its reduction. Fire Sci Rev 2:4

18. Zhao L, Dembsey NA (2008) Measurement uncertainty analysis for calorimetry apparatuses. Fire Mater 32:1-26

Publisher's Note Springer Nature remains neutral with regard to jurisdictional claims in published maps and institutional affiliations. 